\title{
Decision Aid Framework For Investments in Environment (DAFFIE). Investing in the environment; when is it too much?
}

\author{
S. Vanassche, L. Vranken \& P. Vercaemst \\ VITO, Flemish Institute for Technological Research, Belgium
}

\begin{abstract}
DAFFIE provides a methodology to estimate the economic feasibility of environmental investments. Typically, (mandatory) environmental investments are unprofitable as such so that classical investment analysis provides insufficient insights to assess their economic feasibility. Therefore, we evaluate whether an industry or company has the carrying capacity for extra costs associated with the introduction of environmental measures. In the DAFFIE evaluation method, an investment is economically feasible when an industry or company is able to maintain or strengthen its competitiveness which is defined as the ability to maintain sufficient liquidity and solvency and to earn a return from activities that exceeds the cost of capital in the long run. This implies the use of financial ratio analysis. DAFFIE starts from the annual accounts of an (average) company. The impact of the investment options is simulated into projected accounts. Eight key financial ratios are calculated for the projected statement with the investment options included and excluded. Finally, the evolution of the key ratios is benchmarked against a reference group (e.g. total industry in Flanders) to come to a conclusion on the feasibility of the investment options. This methodology highlights the potential impact of unprofitable environmental investments on the financial position of a company or industry. The results are used to support environmental policy makers or to objectify discussions between companies which are confronted with additional investments due to environmental legislation, and governments which issue emission permits. The paper describes the DAFFIE methodology in more detail and illustrates its use with practical cases.
\end{abstract}

Keywords: environmental investment, financial ratio analysis, economical feasibility, calculation model. 


\section{Introduction}

By definition, environmental investments are implemented with the purpose of protecting the environment, often under pressure of environmental policy (e.g. permit conditions) $[5,6]$. As a consequence, evaluating this kind of mandatory investments by 'classical' investment analysis, such as the payback time, the net present value or the internal rate of return provides insufficient insights in the discussion between industries and authorities. Rather than evaluating the (un)profitability of these investments, our aim is to evaluate whether an industry or company has the carrying capacity for the extra costs associated with environmental investments.

In the DAFFIE evaluation method, an environmental investment is evaluated as economically feasible when an industry/a company is able to maintain or strengthen its competitiveness in the short and in the long run. Competitiveness is hereby described as the ability to maintain sufficient liquidity and solvency and to earn a return from activities that exceeds the cost of capital in the long run [4]. This definition implies the use of financial ratio analysis.

In this paper, we first highlight the merits of DAFFIE compared to existing methods for evaluating environmental investments. Second, the method itself including the main calculation steps is elaborated. Finally, the role of DAFFIE in the decision process concerning environmental investments is clarified.

\section{Merits of DAFFIE}

Quite surprisingly, there is hardly any literature on the evaluation of environmental investments [7]. However, a number of practical methods exist such as Reference Values [4] an $\mathrm{MIOW}^{+}$[3]. While these methods provide a suitable base for the evaluation of the economic feasibility of environmental investments, they do entail some important disadvantages and shortcomings which are the main reason for developing a new decision aid tool.

First, the method of Reference Values [4] implies calculating the proportion between the costs of the environmental investment and a number of financial parameters. The proportion between the yearly net costs of the investment and turnover, gross added value and operating profit of the sector or company over four years are determined. In addition the share of the environmental investment of the total investments is determined. These proportions are then related to cutoff points, which allow classifying each of the proportions as 'unacceptable', 'further discussion needed' or 'acceptable'. The main shortcoming of this approach is that a large number of environmental investments fall within the range where further discussion is needed and therefore it provides no conclusive judgement about the economic feasibility of different types of environmental investments.

Second, $\mathrm{MIOW}^{+}[3]$ is a model that allows one to estimate the consequences of an environmental investment for the economic situation of an individual company. It takes the financial situation in to account as well as the company's competitive position. The main disadvantage of this model is that it is designed 
for evaluation of investments for large individual companies. Hence, it is not suitable to evaluate the viability of environmental investments for entire industries or SME's.

DAFFIE has the advantage that it can be applied to an entire industry as well as to an individual company and to large as well as small- and medium-sized enterprises. In addition, DAFFIE provides a more conclusive outcome for all types of environmental investments. Furthermore, DAFFIE benchmarks each firm or industry against a reference group and uses this relative position, rather than absolute boundaries for financial ratios, to determine the economic feasibility of environmental investments.

\section{Methodology}

\subsection{DAFFIE framework captured in an Excel-based tool}

Figure 1 shows the general overview of the steps taken within the DAFFIE framework.

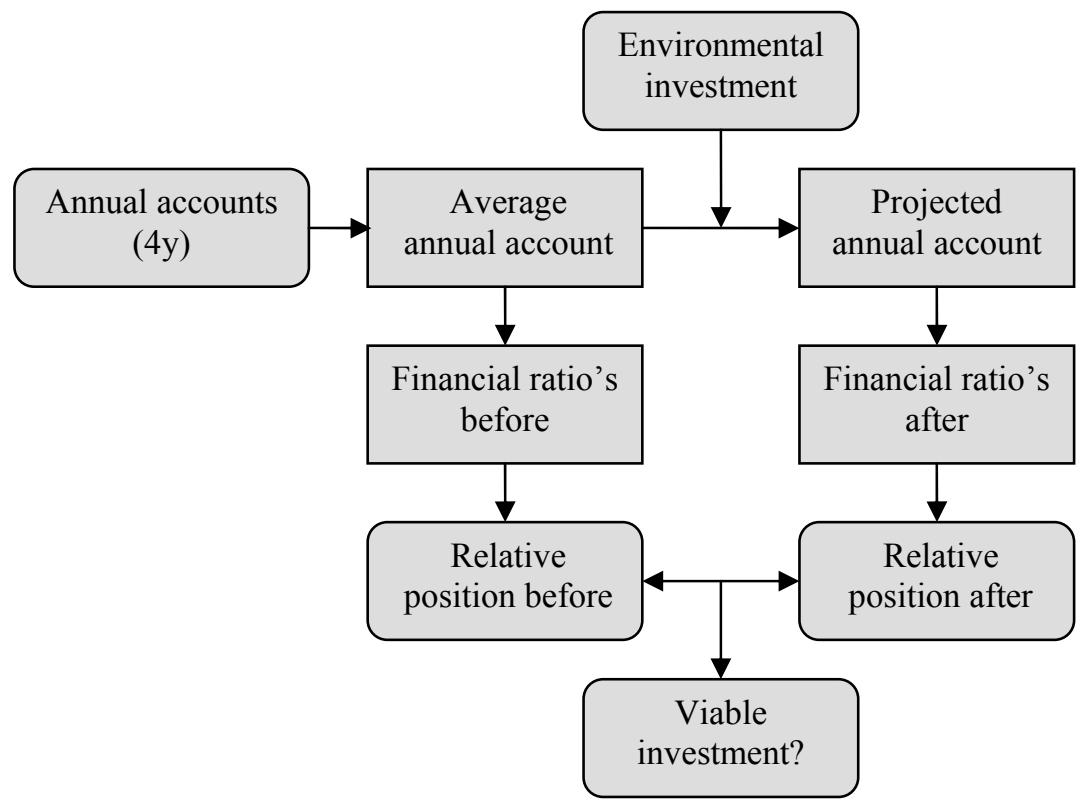

Figure 1: Calculation steps within the DAFFIE framework.

First, the necessary financial data is extracted from the company's annual accounts of the four latest years available. This information is used to construct. The accounts are averaged out over four years in order to flatten out yearly fluctuations into an 'average annual account'. Next, input data concerning the environmental investment options is needed in order to simulate a projected annual account on the basis of the average annual account taking the net costs of 
the environmental investment options into account. Financial ratios are then calculated for the actual as well as the projected annual account. In a final step the relative position of all calculated ratios is compared to the ratios from a reference group (e.g. food industry in Flanders).

The comparison between the relative position of the ratios before and after the environmental investment then serves as an objective starting point for the discussion of the viability of the investment in question.

In order to ease these extensive calculations, we designed a tool as an Excelworkbook containing a number of input fields, calculation sheets and output fields. This tool is in first instance designed to fit the Belgian accounting system as it automatically extract the needed financial data from a database containing all deposited annual accounts of Belgian companies.

\subsection{Defining an average company}

DAFFIE can be used not only for analysis at the level of an individual company, but also at the level of an industry, for example to determine sectoral Best Available Techniques. The annual account then is drawn up for an artificial average company on the basis of the account statements of all companies in the industry over four years considered.

More homogenous groups of companies will result in more representative annual accounts when averaged out. Furthermore, age and size of the company have proven to be important determinants for differences in viability of companies [1]. When determining the average company of a sector it is thus appropriate to subdivide the sector in classes according to age and size. When the number of companies in a sector is small this subdivision can however be impracticable.

Moreover, attention should be paid to examining whether the financial years of the companies involved actually consist of twelve months. If this is not the case the profit-and-loss account has to be recalculated proportionally.

\subsection{Taking environmental costs and yields into account}

Once the average annual statement is drawn up, the costs and revenues associated with the environmental investments have to be taken into account. Table 1 shows the required input that is needed to record the impact of the environmental investment into a projected financial statement.

The impact of investment expenditure, operational and maintenance costs, additional income, avoided costs and depreciation as well as the impact of an additional loan on the balance sheet and profit-and-loss account are all taken into account.

Certain assumptions need to be made regarding the amounts involved, the way it is financed, the depreciation rate and taxes. These can be easily be adjusted in different scenarios.

On the basis of the average and projected accounts, financial ratios are calculated representing respectively the financial health of the sector or company before and after the implementation of the investment. 
Table 1: $\quad$ Input cost components for DAFFIE.

\begin{tabular}{|c|c|}
\hline Cost component & Unit \\
\hline \multicolumn{2}{|l|}{ Investment amount } \\
\hline Expenditure on pollution control equipment & $\mathrm{k} €$ \\
\hline Installation expenditure & $\mathrm{k} €$ \\
\hline \multicolumn{2}{|l|}{ Additional parameters } \\
\hline Economic life span & years \\
\hline Depreciation Installation Expenditure & yes/ no \\
\hline Financed with own funds & $\%$ \\
\hline Term of debt & years \\
\hline Interest rate of debt & $\%$ \\
\hline \multicolumn{2}{|l|}{ Operating and maintenance cots } \\
\hline Yearly personnel costs & $\mathrm{k} €$ \\
\hline Other yearly operating and maintenance costs & $\mathrm{k} €$ \\
\hline \multicolumn{2}{|l|}{ Additional income and avoided costs } \\
\hline Yearly income & $\mathrm{k} €$ \\
\hline Yearly avoided costs & $\mathrm{k} €$ \\
\hline \multicolumn{2}{|l|}{ Other } \\
\hline Corporate tax rate & $\%$ \\
\hline
\end{tabular}

Ooghe et al [2] developed an intuitive failure prediction model based on the eight financial ratios represented in Table 2. The four major areas of financial health, added value (AV), profitability (P), solvability (S) and liquidity (L) are covered by this group of ratios. The average of the logit values of these ratios forms the FiTo ${ }^{\circledR}$-score which is an indicator of the general financial health.

Table 2: $\quad$ Financial ratios used to assess financial health.

\begin{tabular}{|l|l|}
\hline Ratio & \\
\hline 1. Gross added value / personnel costs & $\mathrm{AV} / \mathrm{P}$ \\
\hline 2. Net return on operating assets before taxes & $\mathrm{P}$ \\
\hline 3. Net return on shareholders funds after taxes & $\mathrm{P}$ \\
\hline 4. Self financing quote & $\mathrm{P} / \mathrm{S}$ \\
\hline 5. Financial independence ratio & $\mathrm{S}$ \\
\hline 6. Short term financial debt ratio & $\mathrm{S}$ \\
\hline 7. Coverage of external liabilities by cash flow & $\mathrm{R} / \mathrm{S}$ \\
\hline 8. Net treasury ratio & $\mathrm{L}$ \\
\hline
\end{tabular}

The eight financial ratios and their corresponding FiTo ${ }^{\circledR}$-score are expressed as a percentile score with respect to a reference industry (e.g. total industry in Belgium). This allows quantification of the influence of the investment on the financial situation. 


\section{Decision framework}

Figure 2 visually presents the financial situation before and the estimated financial situation after the implementation of an environmental investment. The eight numbered axes each depict one financial ratio in accordance with the numbering in table 2 . The ratios are represented as percentile values with respect to the reference industry 'total industry in Flanders'. For instance a percentile value of 60 for ratio 1 means that the average company from the sector in question has a larger gross value added over personnel costs than $60 \%$ of the companies from the reference group.

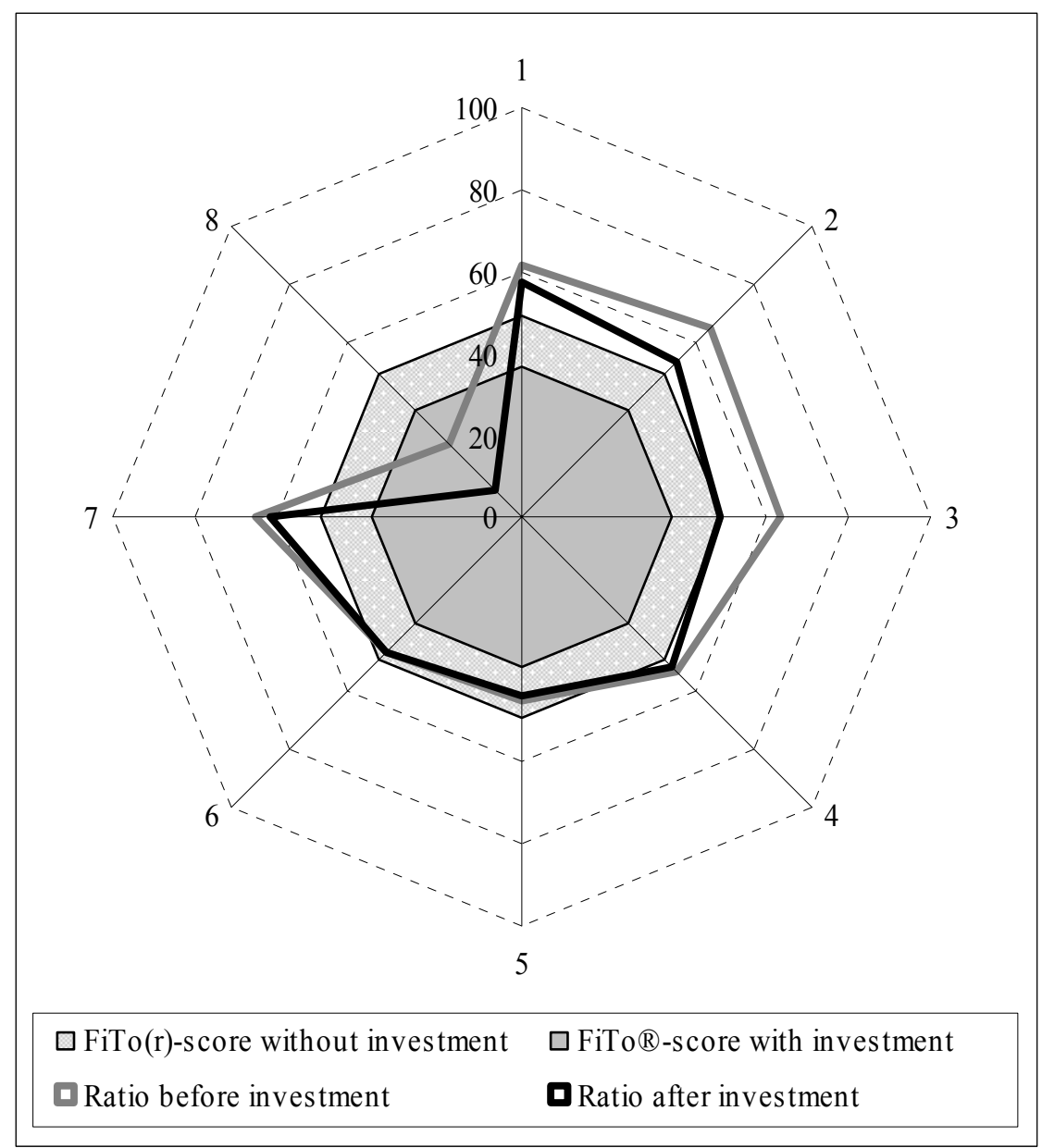

Figure 2: Visualisation of the financial impact of an environmental investment. 
The shaded areas in the diagram in figure 2 represent the percentile position of the $\mathrm{FiTo}^{\mathbb{B}}$-score [2] indicating the general financial health of the average company within the sector in question. Corresponding with the financial ratios, the FiTo ${ }^{\circledR}$-score is also depicted for an average company before the investment (light grey area) and for the estimated average company after the environmental investment (dark grey area).

The financial ratio analysis and FiTo ${ }^{\circledR}$-score intuitively provide two manners of evaluating the viability of an environmental investment. In the first manner the financial ratios are examined individually or within their area of financial health; added value, profitability, solvability and liquidity. When at least one ratio worsens unacceptably it can be stated that the environmental investment is not viable. In the second manner of evaluation, the general financial health is taken into account by assessing the worsening of the FiTo ${ }^{\circledR}$-score by the implementation of an environmental investment. Both manners can complement each other. Further investigation and application of the framework to a number of industry case-studies will help to clarify which worsening of financial ratios and $\mathrm{FiTo}^{\circledR}$-score are acceptable for an economic feasible investment.

\section{Conclusion}

The DAFFIE methodology provides valuable insight in the possible effects of (unprofitable) environmental investments on the financial position of a company or industry. This information can be used to objectify discussions between companies confronted with environmental legislation and governments for environmental permitting cases or as policy support.

In order to ease calculations a calculation model is developed for the Belgian situation. This model can be adapted to meet accounting specifications in different regions or to contain other financial ratios.

At the moment a number of industry case studies are being carried out in order to validate the model and provide more insight in the evaluation of the projected financial situation after the implementation of the investment. Further attention is also paid to establishing the limiting conditions for the application of DAFFIE.

\section{References}

[1] H. Ooghe, C. Spaenjers, P. Vandemoere, The Financial state of the Belgian companies 2005, Intersentia, 2005, Gent.

[2] H. Ooghe, C. Spaenjers, The financial state of the Belgian companies 2006; Ratios and total score on the basis of the FiTo ${ }^{\circledR}-$ meter 1995-2006, Department of Accountancy and Corporate Finance Ghent University Working Paper 2006/380, April 2006, Gent, 22 p.

[3] K.F. Van der Woerd, I.A.W van Rijn., S. Rosdorff, E. Masurel, Y.M. van Everdingen en R.B. Dellink, $\mathrm{MIOW}^{+}$; background to the model, Institute for Environmental Studies, Vrije Universiteit Amsterdam, 1995. 
10 Environmental Economics and Investment Assessment II

[4] P. Vercaemst, BAT: When do Best Available Techniques become Barely Affordable Technology?, BAT-centre VITO, May 2002, Mol.

[5] VROM, Kosten en baten in het milieubeleid: definities en berekeningsmethoden, 1998, Den Haag, 554 p.

[6] LNE, Milieubeleidskosten - begrippen en berekeningsmethoden, Brussel, $41 \mathrm{p}$.

[7] European IPPC Bureau, Reference document on economics and cross-media effects, European Commission, July 2006, Sevilla. 